\title{
Announcement: New Editor for Physical Review Special Topics-Accelerators and Beams
}

Bob Siemann has recently stepped down as the Editor of Physical Review Special Topics Accelerators and Beams (PRST-AB). As the founding Editor of PRST-AB, Bob served for nine years. Under his leadership PRST-AB has grown steadily in size and importance, and is now an established journal with growing influence. We are deeply grateful for Bob's inspiration and energy in creating this unique journal.

We are happy to announce that Frank Zimmermann of CERN has agreed to take on the Editorship of PRST-AB. Frank received his Ph.D. from Hamburg University in 1993. Before joining CERN, he worked at DESY and SLAC. He has also contributed to studies at FNAL and KEK. Frank is an APS Fellow, and a member of the EPS-AG. He has been a PRL Divisional Associate Editor since 2001, and has served as an elected Member at Large of the Executive Committee of the APS Division of Physics of Beams. We have every expectation that Frank will continue to strengthen and develop PRST-AB, and to carry on the work begun so ably and energetically by Bob Siemann.

Published 25 April 2007

Gene D. Sprouse

Editor-in-Chief

American Physical Society

DOI: 10.1103/PhysRevSTAB.10.040001

PACS numbers: 01.10.Cr, 01.30.-y, 01.60.+q 